\title{
FACTORS FACILITATING BUSINESS SERVICE CENTRE GROWTH IN THE BALTIC REGION IN THE CONTEXT OF THE EUROPEAN UNION
}

\author{
Linda Trapane ${ }^{1}$, Mg.oec.; Modrïte Pelse ${ }^{2}$, Dr.oec. \\ ${ }^{1,2}$ Faculty of Economics and Social Development, Latvia University of Life Sciences and Technologies
}

\begin{abstract}
Due to increasing globalization and multinational corporation interest to operate in cost-efficient way, outsourcing and shared service centre creation trend has increased growth of business service centre (BSC) sector globally as well as in the Baltic region. Based on multiple favourable reasons, use of outsourcing and shared service centres have become an operational strategy for many organizations, driven by company's ability to benefit from economies of scale and process transfer to less expensive locations. Baltic States represent one of the most attractive destinations for BSC expansion compared to other European Union (EU) countries. BCS growth in the region can be explained by it's educated, cost-competitive workforce, advantageous geographical location, language proficiency and IT infrastructure as well as attractive economic and business environment. Currently Baltic States demonstrate advantage among other EU Member States in the development of BSC sector, but crucial role is played by institutions in each of the mentioned countries. Institutions in Latvia have identified several priority sectors in terms of foreign investment attraction, while Lithuania has indicated BSC sector as their priority field but Estonia is more focusing on IT and start-up environment development.
\end{abstract}

Key words: Business Service Centres, Outsourcing, Shared Service Centres.

JEL code: R10; M1; F10

\section{Introduction}

In today's dynamic environment, various processes are affected by globalization and technological development, thus changing the structure and organization of different systems, which are mainly influenced by the availability of information and its exchange within a short period of time. As many activities can be done remotely, the need for physical proximity is diminished. Due to mentioned aspects as well as company's interest to operate in cost-efficient way, the use of outsourcing and shared service centres has become a common trend and increased business service centre growth globally as well as in the Baltic region. In this context, term BSC includes three organizational models: shared service centre's (SSC's) business process outsourcing (BPO) and Information Technology Outsourcing (ITO).

The aim of the paper is to describe and evaluate factors contributing to the development of business service centre in Baltic Region in the context of European Union. Research object: factors facilitating business service centre growth. Research object includes following factors - average hourly rate, foreign language knowledge, educational attainment level and comparison of countries by business environment attractiveness. To obtain a broader view of the subject matter an expert interview was conducted. Tasks that were set to achieve the goal: 1 . reflect on aspects of theoretical framework for Business Service Centres; 2. analyse factors contributing to the development of business service centre in the Baltic States in comparison of European Union countries; 3. learn the business service centre sector development trend within the Baltics States. Following methods were used during the work: compilation and analysis of literature, calculation of statistical indicators, expert interviews for qualitative data.

\section{Research results and discussion}

Establishment of business service centres for administrative functions began in America in the mid-1980s. The creation and operation of such service centres is still ongoing. Improvement and

\footnotetext{
${ }^{1}$ Author: Linda Trapane Tel: +371 26146113 E-mail address: linda.trapane@inbox.IV

2 Author: Modrite Pelse Tel: +371 29483220 E-mail address: modrite.pelse@llu.Iv
} 
further development is often associated with the use of innovative solutions for operational functions. Information technologies and increasing globalization contributes to the establishment of business service centres outside the country of parent company. The motivation to outsource non-core activities varies but might include cost reduction, headcount reduction, access to greater expertise and technology, a kenned focus on core activities and better operational flexibility (Rotwell A.T., 2011). The consolidation of processes in BCS allows companies to benefit from economies of scale and process transfer to less expensive locations.

As defined, business process outsourcing is the contracting of non-primary business activities and functions to a third-party provider (Techopedia), however in the context of business service centres, not always it has to be third-party provider. Alternative to outsourcing is shared service centre in which activities previously located in business units or head office are retained within the organization but aggregated into a new central unit which remains in connection with mother company (Rotwell A.T., 2011). Both strategies reduce complexity and thus foster the streamlining of value chains by restructuring administrative functions. However, SSCs add value not merely through simple costcutting like outsourcing, but by turning support activities into core-activities as well, results in the development of new competencies (Richter P.C., 2017). Because of the use and deployment of business service centres depends on companies needs and its business in general, there is No single and complete definition that fits all functional centres of both outsourcing and shared services (Furlong S., 2012).

Central and Eastern Europe (CEE) represents one of the most attractive destinations for SSC globally, where it is predicted that business services in CEE will continue to grow at an average of $30 \%$ annually (Koval O., 2016). The reason for the popularity of the region is complex but can be characterized by several factors such as attractive environment, favourable tax regime, available labour advantages due to lower salaries, as well as language proficiency and time zone to cover the part of Europe operations. In addition to the mentioned advantages, NATO and European Union (EU) membership could also play significant role, as starting from this time expansion in CEE as well as in Baltic States significantly increased (Marciniak R., 2014).

BSC growth in specific regions is determined by several factors. Labour cost can be one of the most important indicators at the time of assessing the potential location of a service centre. As defined by Eurostat: "Labour cost or total labour cost is the total expenditure borne by employers for employing stuff. Total labour cost consists of employee compensation, vocational trainings and other expenditures minus any subsidies received" (Eurostat, Labour cost, 2018). Hourly labour costs gathered in Figure 1.

According to available statistical information, in 2017 the average labour cost per hour between the European Union countries was $€$ 21.5. Although the average value was $€ 21.5$, there is a significant difference in labour costs between member states, where the average hourly rate varies from as low as $€ 4.9$ in Bulgaria to $€ 42.5$ in Denmark. Comparing the obtained indicators with the situation in the Baltic States, it can be concluded that average labour cost per hour in the Baltic region in 2017 was 2.3 times lower than the EU average, respectively $€$ 9.3. Resulting data reflect the average hourly labour costs in the EU Member States, with significant cost differences between them. 


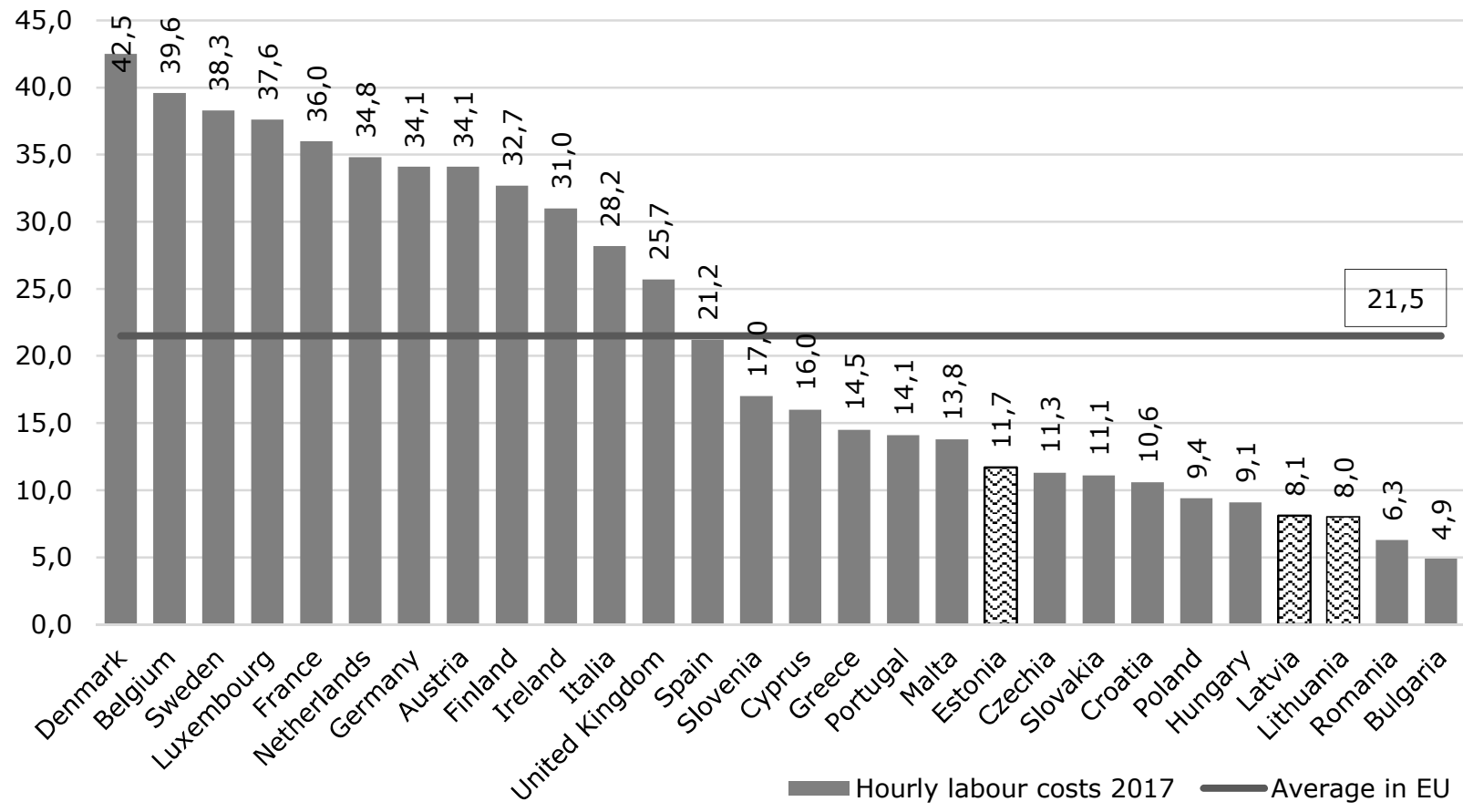

Source: author's created, using Eurostat data 2018

Fig. 1. Hourly labour cost in euro for European Union countries, 2017

Being able to communicate in multiple languages is particularly important when working in an international business environment. Communication with customer or business partner in their native language is one of the first steps to productive and mutually clear cooperation that leads to long lasting and sTable business relationships. Information about foreign language skills in EU countries has been summarized in Figure 2.

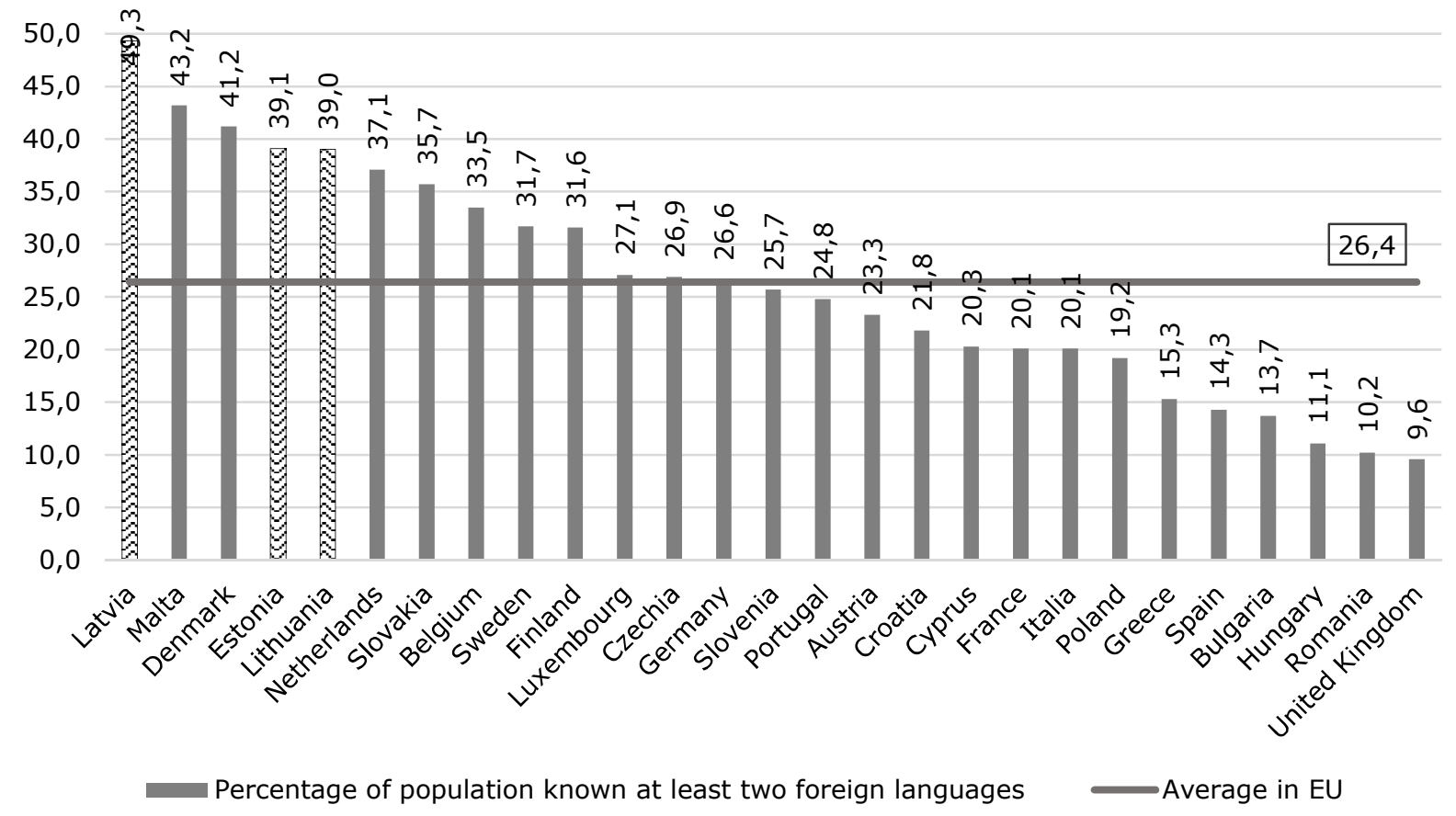

Source: author's created, using Eurostat data 2017

Fig. 2. Percentage of population with knowledge of at least two foreign languages, 2016

According to Eurostat data, in average $26.4 \%$ of the population in EU in addition to their native language has knowledge of at least two additional languages. The highest percentages are reported in Latvia, Malta and Denmark, while the lowest results are in Hungary, Romania and United Kingdom. 
It is necessary to highlight the results in Baltic States as they are significantly higher than the EU average.

In addition to already mentioned factors, also the level of education and available talent pool plays significant role in the process of region evaluation. According to the available information, author concludes that the work in BSC is diverse and covers a wide range of services to be provided, thus the level of qualification of the employed varies depending on the specific nature and complexity of the work. Figure 3 represents the percentage of third to eighth level graduates among EU Member States, using the International Standard Classification of Education (ISCED) level system. Obtained results are grouped into two parts - the percentage of third to fourth level education and fifth to eighth.

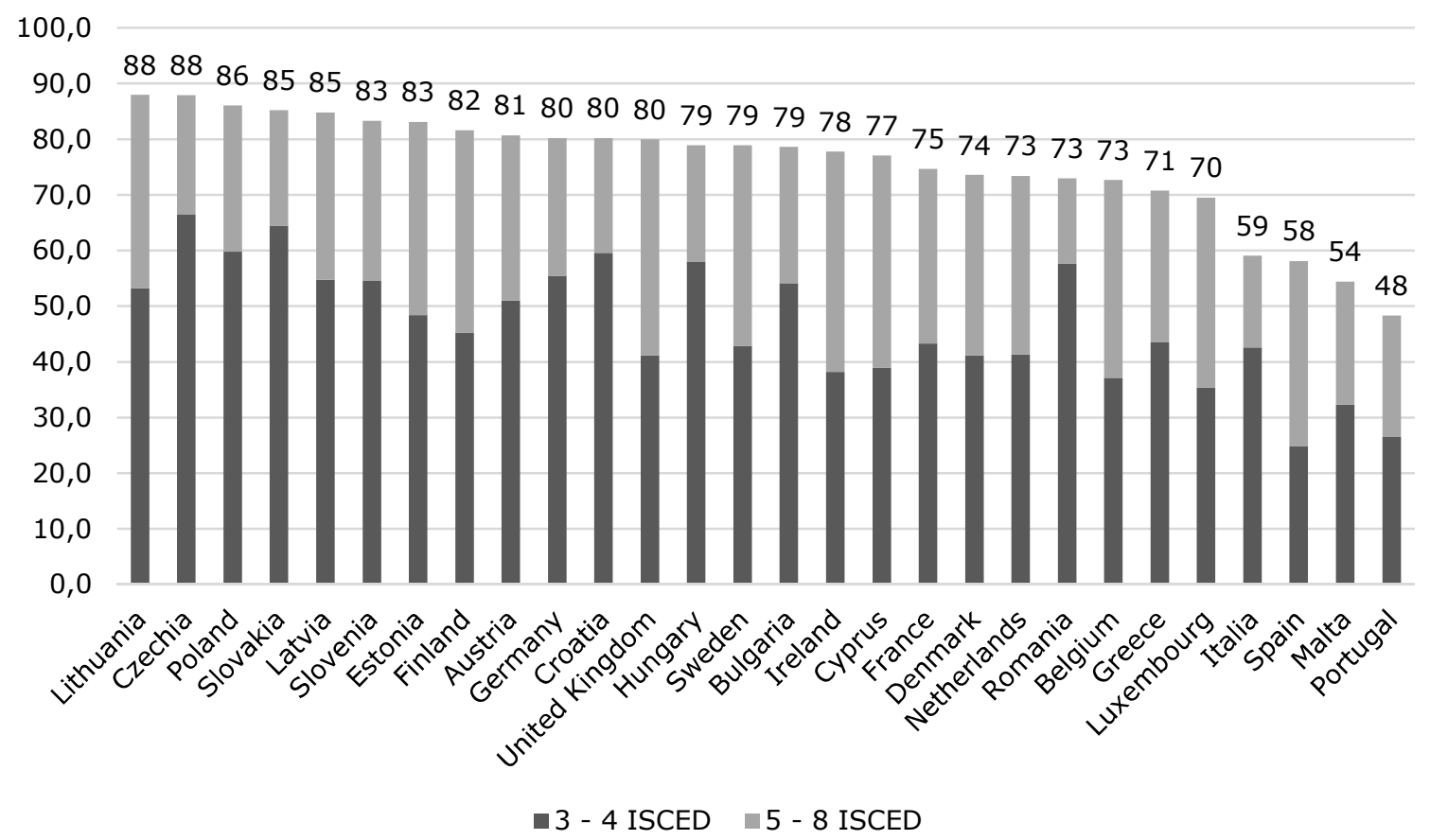

Source: author's created, using Eurostat data 2018

Fig. 3. Population by educational attainment level, 2017 ( \%)

According to presented data in Figure 3, author concludes that Lithuania and the Czech Republic have the highest percentage of people who have obtained education in both groups. With a small percentage difference, they are followed by Poland, Slovakia and Latvia but countries with the lowest rates are Italy, Spain and Portugal.

So far, analysis of the data support potential of the Baltic States for future development in the BSC sector but as attraction of foreign investment is closely related to the business environment, author will also look at the positions of EU member states in the Doing Business rank for 2019. The World Bank's annual Doing Business 2019 report is the sixteenth volume of this study. The data gathered in publication describes ten areas related to the business environment, analysing their contributing and restrictive aspects. This study presents information on the economies of 190 countries worldwide, thus generating a range of 1 to 190. Information on EU Member States in Doing Business 2019 study has been summarized in Table 1. 
Obtained ranks in Doing Business 2019 by EU Member States

\begin{tabular}{|l|c|c|c|c|c|c|c|}
\hline \multicolumn{1}{|c|}{ Country } & Rank & Country & Rank & Country & Rank & Country & Rank \\
\hline Denmark & 3 & Latvia & 19 & France & 31 & Bulgaria & 50 \\
\hline United Kingdom & 7 & Germany & 20 & Netherlands & 32 & Croatia & 51 \\
\hline Sweden & 9 & Austria & 22 & Slovenia & 37 & Belgium & 52 \\
\hline Estonia & 12 & Poland & 27 & Slovakia & 39 & Cyprus & 53 \\
\hline Finland & 13 & Spain & 28 & Romania & 45 & Luxembourg & 63 \\
\hline Lithuania & 16 & Portugal & 29 & Italy & 46 & Greece & 67 \\
\hline Ireland & 17 & Czech Republic & 30 & Hungary & 48 & Malta & 84 \\
\hline
\end{tabular}

The ranking of the countries listed in the Table is based on a comparison of the economies of all 190 countries. Although Denmark ranks third in the overall ranking, its business environment is best rated among EU Member States, followed by Great Britain and Sweden. Positive is the fact that countries in the Baltic region rank among the top 20 of all and among top 10 in the EU. Estonia has the highest ranking among the three neighbouring countries, followed by Lithuania and Latvia.

Work in the BSC sector is closely linked to the use of information technologies, so mobile internet speed is an important factor. According to 2018 study of internet speed measurement service "OOkla", all three Baltic countries ranked among the top twenty countries with the fastest mobile internet in the world. Based on "Worldwide broadband speed league 2018" mobile testing in 200 countries, Latvia ranks thirteenth, Estonia fifteenth and Lithuania seventeenth, showing their potential and advantages regarding this aspect (Goya, C., 2018).

Summarizing obtained information, author concludes that Baltic States demonstrate advantage among other EU Member States, emphasizing the availability of both a skilled but cost-competitive workforce and a positive assessment of the business environment.

To gain more insights on BSC sector development in Baltic States, an interview was conducted with Latvia Investment and Development Agency representative Monta Geidane. In this context M.Geidane emphasizes the position of government and responsible institutions in each country: "Lithuania is now highly praised and also does better, but it is necessary to understand the interconnections. The question is, who is interested in it all. For Latvia Investments and Development Agency, there have been several priority sectors identified, but in the meantime, Lithuania has clearly indicated that this is their priority and therefore developing their marketing with the purpose of attracting new investors. Thus, Estonia is developing in the IT and start-up environment, it has been set as their primary development direction." According to the information gathered during the interview process, the development of the BPC sector largely depends on the priority of development directions set by the state and other stakeholders, which in turn is closely related to the availability of finance and the potential amount of investment in the sector.

The development of the Baltic State BSC sector is closely related to its geographical proximity to the Scandinavian countries. Following the information gathered during the interview as well as the analysis of available information for largest BCS sector companies in the Baltic region, the author concludes that most of the companies in Baltic Stated are of Scandinavian origin (Finland, Sweden, Norway, Denmark). According to M.Geidane: "When looking at the parent organizations of Latvian companies, in 2017 about 48 \% were from Scandinavian countries, not counting the number of 
people or employees, but exactly the number of companies". There is a similar situation in Lithuania, where Scandinavian companies in 2017 made up $44 \%$ of all companies in the sector and employing $39 \%$ of the sector's employees. Looking at the lines of activity of Lithuanian-based service centres, the author concludes that most, or $80 \%$, support services are provided directly to the Scandinavian region. Similarly, the unifying Baltic and Scandinavian countries have a cultural aspect that is reflected in understanding, work ethics and language skills (Invest Lithuania, 2018).

\section{Conclusions, proposals, recommendations}

1) Analysed indicators confirm advantage of the Baltic States in the context of other EU member states, by providing a set of necessary prerequisites for the development and operation of international business service centres.

2) In the Baltic States, a cost-competitive and skilled workforce is available, as well as an economically attractive environment and modern infrastructure related to information technology and high-quality internet usage.

3) Currently equal development of the SBPC sector can be observed in all Baltic States, however, each country has set different priority directions for further development.

4) The development of the BSC sector is currently priority for Lithuania, which means that additional funds are invested by government to attract potential investors. In Latvia, this is only one of the priority areas, while Estonia is currently focusing on the development of information services and start-up technologies.

5) The development of Baltic State international business service centres is closely linked to its geographical proximity to Scandinavian countries. Scandinavian companies are among the largest market participants and investors in the Baltic States.

\section{Acknowledgements}

The paper was supported by the National Research Programme "Latvian heritage and future challenges for the sustainability of the state" project "Challenges for the Latvian state and society and the solutions in international context (INTERFRAME-LV)".

\section{Bibliography}

1. Eurostat (2017) Number of Foreign Languages Known. Retrieved: https://ec.europa.eu/eurostat/web/education-and-training/data/database Access: 22.10.2018.

2. Eurostat (2018) Hourly Labour Costs 2017. Retrieved: https://ec.europa.eu/eurostat/statisticsexplained/index.php/Hourly_labour_costs Access: 22.10.2018.

3. Eurostat (2018) Labour Cost. Retrieved: https://ec.europa.eu/eurostat/statisticsexplained/index.php?title=Glossary:Average_hourly_labour_cost Access: 15.10.2018.

4. Furlong, S. (2012) Shared Services and Outsourcing. Retrieved: https://www.ssonetwork.com/businessprocess-outsourcing/articles/shared-services-and-outsourcing Access: 15.10.2018.

5. Goya, C. (2018) The 23 Countries in the World with the Fastest Internet Speed. Retrieved: https://www.businessinsider.com/the-23-countries-in-the-world-with-the-fastest-internet-speeds-2018-7 Access: 05.11.2019.

6. Koval O., Nabareseh S., Klimek P., Chromjakova F. (2016) Demographic Preferences Towars Carees in Shared Service Centers: A factor analysis. Journal of Business Research. No 69 pp. 4798-4803.

7. Lithuania's Business Services Report (2018) Retrieved: https://www.investlithuania.com/gbs-report2018/wp-content/uploads/2018/09/GBS-report-2018.pdf Access: 20.10.2018.

8. Lithuania's Business Services Report (2018) Retrieved: https://www.investlithuania.com/gbs-report2018/wp-content/uploads/2018/09/GBS-report-2018.pdf Access: 05.11.2018

9. Marciniak R. (2014) Global Shared Service Trends in the Central and Eastern European Markets. Entrepreneurial Business and Economics Review. No 3.

10. Richter P.C., Bruhl R. (2017) Shared Service Center Research: A Review of the Past, Present, and Future. European Management Journal. No 35 pp. 26-38 
Proceedings of the 2019 International Conference "ECONOMIC SCIENCE FOR RURAL DEVELOPMENT" No 51

Jelgava, LLU ESAF, 9-10 May 2019, pp. 245-251

DOI: $10.22616 /$ ESRD.2019.082

11. Rotwell A.T., Herbert I.P., Seal W. (2011) Shared Service Centers and Professional Employability. Journal of Vocational Behaviour. No 79 pp. 214-252

12. Techopedia. Business Process Outsourcing. Retrieved:

https://www.techopedia.com/definition/13776/business-process-outsourcing-bpo Access: 10.10.2018.

13. The World Bank (2019) Doing Business 2019. Retrieved:

http://www.doingbusiness.org/content/dam/doingBusiness/media/Annual-Reports/English/DB2019report_web-version.pdf Access: 22.10.2018. 